\title{
Finding inflammatory bowel disease genes will lead to a cure
}

\author{
Judy H Cho MD
}

$\mathrm{T}$ he opinion that finding inflammatory bowel disease (IBD) genes will lead to a cure is based on the fact that genetic variation provides a vast reservoir of information specific to individual patients that is only beginning to be acknowledged on a large scale. Complementary to this is that, in many respects, IBD represents an ideal genetic disorder(s). First, the significant role of genetics in IBD is firmly established based on the significant familial clustering observed, combined with significantly higher concordance of monozygotic twins compared with dizygotic twins (1). The diagnostic pathogenic certainty associated with the diagnoses of Crohn's disease (CD) and ulcerative colitis (UC) is high; heterogeneity probably exists in clinically similar cases but is likely relatively limited. Compared with other multigenic disorders, the relevant tissues - the peripheral blood leukocytes and the intestinal tissues - are easy to obtain for expression studies. There are numerous, excellent animal models that exist in IBD (2) for which several lines of evidence provide correlative support in humans. The fact that at least two well-replicated disease associations exist in IBD - nucleotide oligomerization domain 2/caspase activation and recruitment domain 15 (NOD2/CARD15) $(3,4)$ and IBD5 on chromosome $5 q(5,6)$ - holds out the promise that the increased understanding of disease pathophysiology will accrue from genetic approaches.

At least three mechanisms can be defined through which genetics can effect cures for IBD. First, if effective, preventive approaches can be developed, feasibly powered studies will require the identification and prospective follow-up of high-risk individuals which will be best achieved through testing of established IBD genes. Second, the identification of genuine IBD risk alleles will often provide very novel insights into the mechanisms of disease pathogenesis that fundamentally change existing paradigms of disease pathogenesis. Finally, genetic approaches refine the understanding of key pathways that lead to human IBD.

\section{PREVENTING DISEASE: IDENTIFICATION OF THE HIGHEST RISK INDIVIDUALS}

The prevalence of IBD is too low in the general population to anticipate that effective, preventive interventions can be developed on a population-wide basis. Rather, prospective, preventive and epidemiological studies will need to be applied within currently unaffected relatives of IBD probands. These highest risk individuals include monozygotic twins, children of parents who are both affected by IBD, and NOD2/CARD15 homozygous and compound heterozygous relatives of CD probands. In a large trio-based cohort (7) (affected child plus both parents studied), 145 of 1952 (7.4\%) parents of CD children had the disease. Of 69 parents homozygous for the NOD2/CARD15 mutations,
16 (23.2\% risk of CD) had CD (the estimated risk of developing CD given NOD2/CARD15 homozygosity only applies to relatives of CD patients). It was predicted that the risk of siblings of $\mathrm{CD}$ probands developing $\mathrm{CD}$ would be at least comparable to that observed in parents, given the more similar developmental and environmental factors shared by siblings compared with parent-child pairs.

\section{GENETICS PROVIDES NOVEL INSIGHT INTO MECHANISMS OF DISEASE PATHOGENESIS}

The identification of NOD2/CARD15 mutations and their association to $C D$ has resulted in fundamentally different ways of thinking about CD and host-bacterial interactions. It has resulted in a more balanced view by the community at large on the relative importance of the innate arm of the immune system. It has highlighted the importance of intracellular microbial sensing mechanisms, as well as the potential role of alpha-defensins in intestinal immune homeostasis (8-10). Finally, the identification of relatively uncommon amino acid polymorphisms in innate immune receptors provides an important new class of genetic variants that defines interindividual variability in hostenvironment interactions (11).

A new genetics approach that is increasingly being applied to multigenic disorders is the application of genome-wide association studies $(12,13)$. The underlying premise for this approach is that most IBD risk alleles are relatively common in the population (common disease, common variant hypothesis). If multiple functional polymorphisms, each exerting subtle functional effects, are simultaneously required for disease development to achieve the expected population prevalence, each of these risk alleles must be relatively common in the control population. It is estimated that seven million single nucleotide polymorphisms (SNPs) with a minor allele frequency of at least $5 \%$ exist. Because many of these SNPs are in linkage disequilibrium with each other (ie, they 'travel together'), only several 100,000 well-selected SNPs are required to sample much of the common genetic variation in the human genome. Current genetic technologies are presently available to test this magnitude of SNPs. It is anticipated that the testing of 1000 cases and controls each would be adequately powered to identify a significant fraction of contributing risk alleles. Challenges of completing and interpreting genome-wide association studies include pathophysiological heterogeneity, the need for extensive replication and the lack of current analytical framework for testing for locus-locus interactions. Obtaining this extraordinary amount of genetic information on a cohort of patients in whom extensive phenotypical information is available, including expression studies and the capacity to follow prospectively, represents an extremely promising mechanism of identifying important new connections

Division of Gastroenterology, Inflammatory Bowel Disease Center, Yale University, New Haven, Connecticut, USA

Correspondence: Dr Judy H Cho, Division of Gastroenterology, Inflammatory Bowel Disease Center, Yale University, 300 Cedar Street, S115A,

New Haven, Connecticut 06519, USA. Telephone 733-702-5375, fax 773-702-2281, e-mail jcho@medicine.bsd.uchicago.edu 
among genotypes, disease course and effects on disease expression. As information on genetic patterns and functional polymorphisms accrue, and costs for dense genome-wide typing fall, it is likely that comprehensive genetic testing will be more universally used in genetic and translational studies, and ultimately, used in clinical practice.

\section{GENETICS REFINES UNDERSTANDING OF KEY PATHWAY DEFINITIONS}

Many of the crucial pathways that lead to human IBD may have already been identified through various animal models of IBD. A comprehensive understanding of IBD involves integrating information obtained from animal models, functional human polymorphisms and various expression studies from human tissues. One illustrative example (14) involves the mdrla (-/-) knock-out model of IBD, which spontaneously develops colitis. Genetic variants within the MDR1 gene or pathway that result in decreased expression or function are strong candidates for disease association. The MDR1 gene is a member of the ATP-binding cassette of membrane transporters and is located within a region of suggestive linkage on chromosome 7q. Polymorphisms within the gene that affect gene expression and activity have been reported. Some positive studies of IBD association have been reported, but definitive replication has not occurred. However, the finding of decreased expression of MDR1 in intestinal tissues from CD and UC provides strong

\section{REFERENCES}

1. Bonen DK, Cho JH. The genetics of inflammatory bowel disease. Gastroenterology 2003;124:521-36.

2. Elson CO, Cong Y, McCracken VJ, Dimmitt RA, Lorenz RG, Weaver CT. Experimental models of inflammatory bowel disease reveal innate, adaptive, and regulatory mechanisms of host dialogue with the microbiota. Immunol Rev 2005;206:260-76.

3. Hugot JP, Chamaillard M, Zouali H, et al. Association of NOD2 leucine-rich repeat variants with susceptibility to Crohn's disease. Nature 2001;411:599-603.

4. Ogura Y, Bonen DK, Inohara N, et al. A frameshift mutation in NOD2 associated with susceptibility to Crohn's disease. Nature 2001;411:603-6

5. Peltekova VD, Wintle RF, Rubin LA, et al. Functional variants of OCTN cation transporter genes are associated with Crohn disease. Nat Genet 2004;36:471-5.

6. Rioux JD, Daly MJ, Silverberg MS, et al. Genetic variation in the $5 \mathrm{q} 31$ cytokine gene cluster confers susceptibility to Crohn disease. Nat Genet 2001;29:223-8.

7. Silverberg MS, Duerr RH, Brant SR, et al. Refined genomic localization and ethnic differences observed for the IBD5 association with Crohn's disease. Eur J Hum Genet 2006. (In press)

8. Wehkamp J, Harder J, Weichenthal M, et al. NOD2 (CARD15) mutations in Crohn's disease are associated with diminished mucosal alpha-defensin expression. Gut 2004;53:1658-64.

9. Kobayashi KS, Chamaillard M, Ogura Y, et al. Nod2-dependent regulation of innate and adaptive immunity in the intestinal tract. Science 2005;307:731-4. correlative support in human disease that the MDR1 pathway is likely important, meriting therapeutic consideration (15). The MDR1 promoter includes elements for beta-catenin and $\mathrm{T}$ cell factor (16), and the pregnane $\mathrm{X}$ and retinoic acid receptor (17) heterodimeric transcription factors. Recently, the association of a polymorphism to IBD genes in pregnane $\mathrm{X}$ receptors that affect expression of MDR1 has been reported, which further highlights the importance of the MDR1 pathway in IBD pathogenesis (18).

\section{CONCLUSIONS}

It is anticipated that in the not too distant future, the cost-effective means of comprehensively genotyping functional human polymorphisms and/or resequencing individual genomes will be available as a diagnostic tool for clinicians. This future diagnostic tool will provide a wealth of crucial information; the inherent complexity of interpreting this wealth of data should not deter us from starting this inevitable process of discovery. Education of current and future physicians in genetics will be an integral part of this process. The development of new IBD therapeutic algorithms would ideally involve a creative integration of therapeutic interventions with information on individual genetic backgrounds. The specific therapeutic challenges in IBD include its chronicity, intermittence and paramount need for safety. These challenges can best be met through individualized approaches and integrating knowledge of genetic factors.

10. Wehkamp J, Salzman NH, Porter E, et al. Reduced Paneth cell alpha-defensins in ileal Crohn's disease. Proc Natl Acad Sci USA 2005;102:18129-34

11. Cook DN, Pisetsky DS, Schwartz DA. Toll-like receptors in the pathogenesis of human disease. Nat Immunol 2004;5:975-9.

12. Hirschhorn JN, Daly MJ. Genome-wide association studies for common diseases and complex traits. Nat Rev Genet 2005;6:95-108.

13. Wang WY, Barratt BJ, Clayton DG, Todd JA. Genome-wide association studies: Theoretical and practical concerns. Nat Rev Genet 2005;6:109-18

14. Panwala CM, Jones JC, Viney JL. A novel model of inflammatory bowel disease: Mice deficient for the multiple drug resistance gene, $m d r l a$, spontaneously develop colitis. J Immunol 1998;161:5733-44.

15. Langmann T, Moehle C, Mauerer R, et al. Loss of detoxification in inflammatory bowel disease: Dysregulation of pregnane $\mathrm{X}$ receptor target genes. Gastroenterology 2004;127:26-40.

16. Yamada T, Takaoka AS, Naishiro Y, et al. Transactivation of the multidrug resistance 1 gene by $\mathrm{T}$-cell factor $4 /$ beta-catenin complex in early colorectal carcinogenesis. Cancer Res 2000;60:4761-6.

17. Geick A, Eichelbaum M, Burk O. Nuclear receptor response elements mediate induction of intestinal MDR1 by rifampin. J Biol Chem 2001;276:14581-7.

18. Dring MM, Goulding CA, Trimble VI, et al. The pregnane X receptor locus is associated with susceptibility to inflammatory bowel disease. Gastroenterology 2006;130:341-8; quiz 592. 


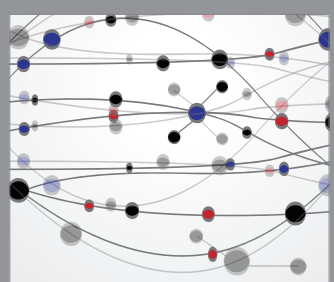

The Scientific World Journal
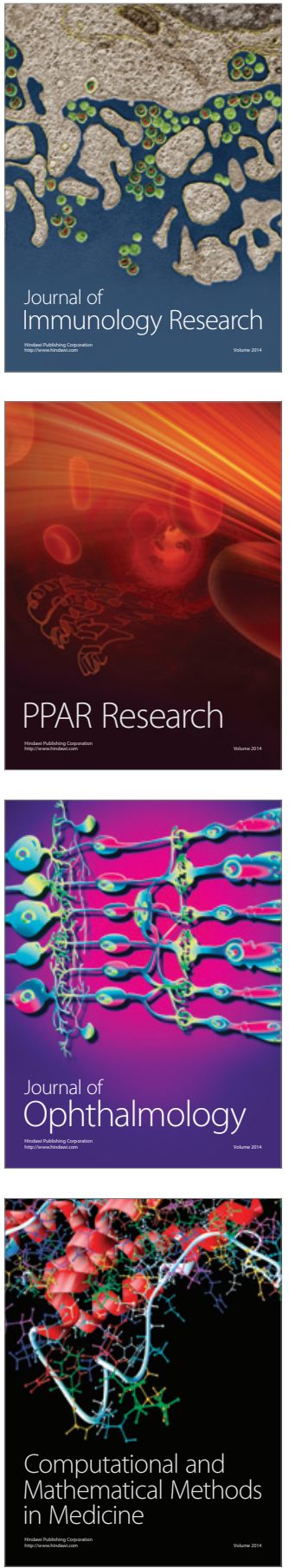

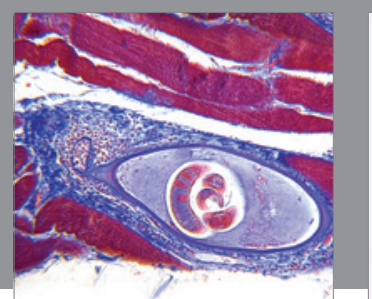

Gastroenterology Research and Practice

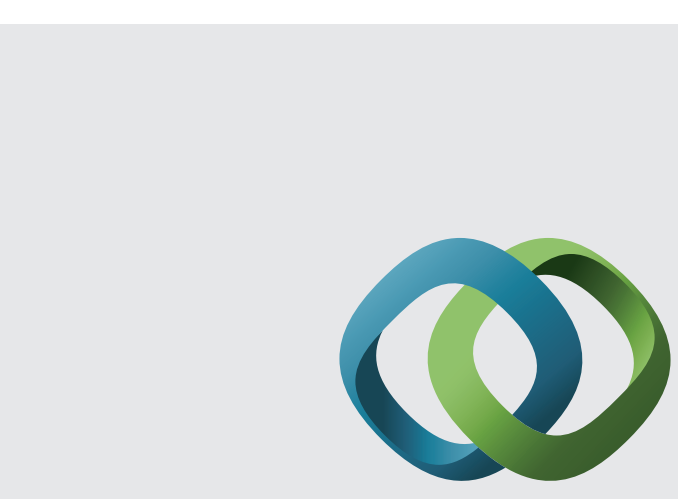

\section{Hindawi}

Submit your manuscripts at

http://www.hindawi.com
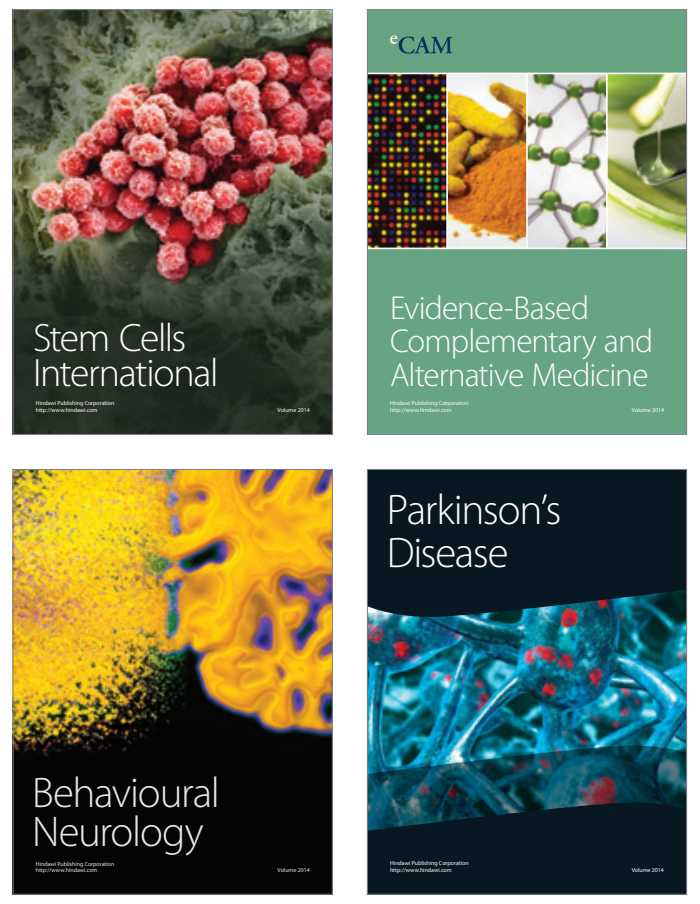
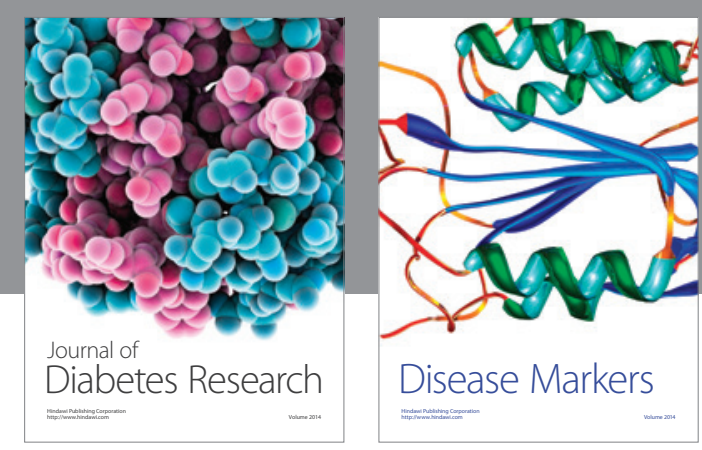

Disease Markers
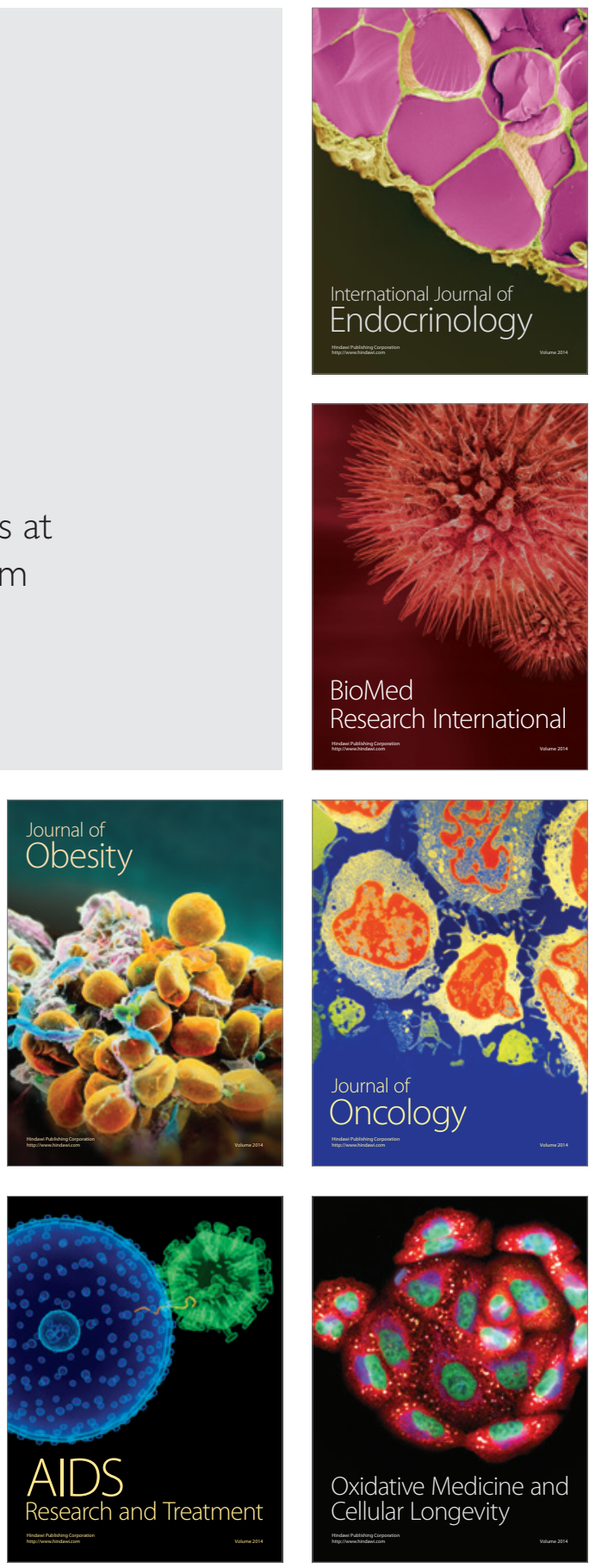